\title{
Inflammatory arthritis associated with inflammatory bowel disease in children
}

\author{
M Desgranges ${ }^{3}$, FM Ruemmele ${ }^{1}$, A Duquesnes ${ }^{2}$, JL Ginies ${ }^{3}$, O Goulet ${ }^{1}$, \\ P Quartier ${ }^{1}$ and B Bader-Meunier*1
}

Address: ${ }^{1}$ Hopital Necker, Paris, France, ${ }^{2}$ Hospices civils de Lyon, Lyon, France and ${ }^{3}$ Centre hospitalo-universitaire d'Angers, Angers, France

* Corresponding author

\author{
from I5th Paediatric Rheumatology European Society (PreS) Congress \\ London, UK. 14-17 September 2008 \\ Published: 15 September 2008 \\ Pediatric Rheumatology 2008, 6(Suppl I):PI35 doi:I0.II86/I546-0096-6-SI-PI35
}

This abstract is available from: http://www.ped-rheum.com/content/6/SI/PI35

(c) 2008 Desgranges et al; licensee BioMed Central Ltd.

\section{Purpose}

To describe the clinical presentation of inflammatory arthritis associated with inflammatory bowel disease (IBD) in children

\section{Methods}

Retrospective study conducted in 3 French pediatric centres. Children presenting with IBD associated with inflammatory arthritis were included.

\section{Results}

Nine children aged from 2.8 to 14.9 years presented with a Crohn's disease associated with arthritis. Rheumatic disease occurred 25 to 41 months before the diagnosis of IBD ( 3 children), 8 to 62 months after the diagnosis of IBD (4 children) or at the same time of IBD ( 2 children). In the first three children, polyarticular form of juvenile idiopathic arthritis and Still's disease were initially diagnosed. IBD was diagnosed 2 to 7 months after the initiation of etanercept ( 2 children) and anakinra ( 1 child). Arthritis developed in children who received corticosteroids, infliximab, methotrexate and/or azathioprine because of IBD. Patients presented with peripheral arthritis, involving knees ( 7 children), ankles ( 5 children), and rarely hips, fingers, elbows and shoulders. 12/18 relapse of arthritis occurred at the same time as relapses of IBD. Abdominal manifestations included diarrhea, anal abscess, abdominal pain, vomiting, and loss of weight. Mean $\mathrm{C}$ reactive protein value and erythrocyte sedimentation rate were 102 $\mathrm{mg} / \mathrm{L}$ and $58 \mathrm{~mm}$ at onset of the disease respectively.

\section{Discussion}

IBD may be diagnosed several years after the occurrence of arthritis and must be searched for in children presenting with arthritis and abdominal involvement and/or weight loss. IBD may develop in children who receive etanercept while infliximab does not prevent the occurrence of inflammatory arthritis. 